\title{
O CORPO COMO MERCADORIA NOS ANÚNCIOS/PERFIS DE HOMENS GAYS NO LAMPIÃO DA ESQUINA E NO GRINDR
}

\author{
EL CUERPO COMO MERCANCÍA EN LOS ANUNCIOS / PERFILES DE HOMBRES \\ GAY EN LAMPIÃO DA ESQUINA Y GRINDR
}

\section{THE BODY AS MERCHANDISE IN THE ADVERTISEMENTS/PROFILES OF GAY MEN IN LAMPIÃO DA ESQUINA AND GRINDR}

\author{
Mesaque Silva CORREIA ${ }^{1}$ \\ Marcos Antônio Ângelo da SILVA ${ }^{2}$ \\ Jamil Oliveira LEITE ${ }^{3}$ \\ Thayna Larissa Soares de OLIVEIRA ${ }^{4}$ \\ Weslley da Silva RODRIGUES ${ }^{5}$
}

RESUMO: O presente trabalho tem como objetivo analisar os anúncios de homens gays no jornal Lampião da Esquina e no aplicativo Grindr, com o intuito de compreender os sentidos atribuídos por estes sujeitos à midiatização do corpo na busca por parceiros em contextos históricos diferentes. Assim como de identificar os aspectos comuns no processo de busca por parceiros nestes meios de socialização e descrever quais parâmetros são utilizados com maior frequência na busca por parceiros nestes instrumentos. Para alcançar os objetivos propostos nos apropriamos dos pressupostos teórico-metodológicos da netnografia. Foram analisados três perfis no Lampião da Esquina e três no Grindr. Para a produção dos dados, utilizamos os dados arquivais contidos nos anúncios do jornal Lampião da Esquina e no aplicativo Grindr. Os resultados da pesquisa evidenciam semelhanças na forma de apresentação dos usuários do Lampião da esquina, com os do Grindr. Assim como encontramos conexões com relação aos aspectos e parâmetros utilizados na busca por parceiros como porte físico, gostos semelhantes, padrões de vida, raça, entre outros. Inferimos, que as práticas utilizadas se assemelham no destaque atribuído ao corpo e ao fator mercantil de tal, portanto, sendo basicamente o corpo enquanto físico e esteticamente agradável o mais atrativo na escolha deles.

PALAVRAS-CHAVE: Corpo. Lgbtqia+. Mercadoria. Mídias sociais.

\footnotetext{
${ }^{1}$ Universidade Federal do Piaú (UFPI), Teresina - PI - Brasil. Professor no Departamento de Métodos e Técnicas de Ensino (DMTE). Doutorado em Educação Física (USJT). ORCID: https://orcid.org/0000-00020258-7111. E-mail: mesaquesilvacorreia@ufpi.edu

${ }^{2}$ Universidade Federal do Piauí (UFPI) - Teresina - PI - Brasil. Mestrando no Programa de Pós-graduação em Ciências Sociais. ORCID: https://orcid.org/0000-0002-5591-6329. E-mail: marcossantonioangelo12@gmail.com ${ }^{3}$ Universidade Federal do Piauí (UFPI) - Teresina - PI - Brasil. Licenciado e Bacharel em Educação Física. ORCID: https://orcid.org/0000-0001-7814-765X. E-mail: jamilcardio4@gmail.com

${ }^{4}$ Universidade Federal do Piauí (UFPI) - Teresina - PI - Brasil. Graduada em Comunicação Social - Jornalismo e Educação Física. Membro do Grupo de Estudo e Pesquisa em Educação e Educação Física Escolar GEPEEFE/UFPI. ORCID: https://orcid.org/0000-0001-9177-2927. E-mail: thaynaoliveira431@gmail.com

${ }^{5}$ Universidade Federal do Piauí (UFPI) - Teresina - PI - Brasil. Graduado em Educação Física. Membro do Grupo de Estudo e Pesquisa em Educação e Educação Física Escolar GEPEEFE/UFPI. ORCID: https://orcid.org/0000-0002-4831-4290.E-mail: weslley_rodrigues@hotmail.com
} 
RESUMEN: Este artículo tiene como objetivo analizar los anuncios de hombres homosexuales en el diario Lampião da Esquina y en la aplicación Grindr, con el fin de comprender los significados que estos sujetos atribuyen a la mediatización del cuerpo en la búsqueda de parejas en diferentes contextos históricos. Así como identificar los aspectos comunes en el proceso de búsqueda de socios en estos medios de socialización y describir qué parámetros se utilizan con mayor frecuencia en la búsqueda de socios en estos instrumentos. Para lograr los objetivos propuestos, nos apropiamos de los supuestos teóricos y metodológicos de la netnografia. Se analizaron tres perfiles en Lampião da Esquina y tres en Grindr. Para la producción de los datos, utilizamos los datos de archivo contenidos en los anuncios del periódico Lampião da Esquina y en la aplicación Grindr. Los resultados de la investigación muestran similitudes en la presentación de los usuarios de Lampião da esquina, con los de Grindr. Así como encontramos conexiones con respecto a los aspectos y parámetros utilizados en la búsqueda de parejas como tamaño físico, gustos similares, niveles de vida, raza, entre otros. Inferimos que las prácticas empleadas son similares en el protagonismo atribuido al cuerpo y al factor mercantil del mismo, por tanto, siendo el cuerpo básicamente físico y estéticamente agradable, el más atractivo en su elección.

PALABRAS CLAVE: Cuerpo. Lgbtqia +. Mercancias. Redes sociales.

ABSTRACT: This paper aims to analyze the ads of gay men in the Lampião da Esquina newspaper and in the Grindr app, to understand the meanings attributed by these subjects to the mediatization of the body in the search for partners in different historical contexts. As well as to identify the common aspects in the process of searching for partners in these means of socialization and to describe which parameters are most frequently used in the search for partners in these instruments. To achieve the proposed objectives, we appropriated the theoretical and methodological assumptions of netnography. Three profiles were analyzed at Lampião da Esquina and three at Grindr. To produce the data, we use the archival data contained in the advertisements of the Lampião da Esquina newspaper and in the Grindr application. The results of the research show similarities in the presentation of users of Lampião da Esquina, with those of Grindr. We also found connections regarding aspects and parameters used in the search for partners such as physical size, similar tastes, standards of living, race, among others. We infer that the practices used are similar in the prominence attributed to the body and to the mercantile factor of it, therefore, the body being basically physical and aesthetically pleasing, the most attractive in their choice.

KEYWORDS: Body. Lgbtqia +. Merchandise. Social media.

\section{Introdução}

Esse artigo inscreve-se nos objetivos do Grupo de Estudos e Pesquisa em Educação e Educação Física Escolar - GEPEEFE/UFPI, certificado no Diretório de Pesquisa do CNPq. A investigação configura-se, portanto, em mais uma contribuição sobre a mercantilização do corpo no contexto da sociedade moderna. É mister salientar que há anos tomamos o corpo humano como objeto de nossas investigações e alavanca metodológica do conhecimento, 
como pode ser constatado nos estudos desenvolvidos por Oliveira (2019) e Silva e Correia (2020).

Desse modo, estamos cientes que no contexto do sistema social capitalista, o mercado e o consumo não se reduzem meramente ao plano físico de bens materiais. O próprio corpo, tanto como entidade física ou simbólica, é agente e alvo de consumo em seus diversos aspectos. Portanto, nada parece escapar ao mercado e ao capital. Além disso, o capitalismo no mundo globalizado lança mão de novas estratégias. Agora, ele é favorecido pelas novas tecnologias da comunicação e mediado pela publicidade.

Dessa forma, faz-se importante compreender, que a chegada e inserção da internet em nossas vidas é uma realidade sem volta. Em todos os campos, e nos diferentes contextos sociais, o uso da internet e das novas tecnologias é uma necessidade que estimula e auxilia na condução do modo de vida das pessoas. Essas novas facetas da vida moderna oportunizam uma variedade de facilidades nos diferentes campos, caracterizando o cotidiano e as relações sociais com acontecimentos de forma rápida e superficiais, assim como contribui para o processo de mercantilização de corpos (OLIVEIRA, 2019; SOARES, BARBOSA, 2020).

Consoante a essa compreensão, é possível inferir que em tempos de veneração do corpo não é apenas o corpo, enquanto entidade física, que interessa ao capitalismo. As imagens como mercadoria constituem também objetos fundamentais de apropriação pelo mercado. Nesse sentido, propomos discorrer sobre a temática do corpo, buscando compreender como são apresentados, exibidos e descritos os corpos gays masculinos diante das ofertas de socialização apresentadas em períodos distintos de nossa sociedade. Dessa forma, um olhar mais atento para o advento da inclusão dos meios digitais no nosso cotidiano torna-se necessário no sentido de compreender como a influência dessas tecnologias abarca a vida dos indivíduos enquanto sociedade.

Assim, apresentamos neste trabalho uma análise das configurações e impressões virtuais acerca dos corpos masculinos no aplicativo de encontro gay "GRINDR". Neste ínterim, buscamos traçar um paralelo com as formas de busca de parceiros realizadas por gays nas décadas de 70 e 80 por meio de anúncios publicados em um jornal específico para este público, o Lampião da Esquina, com o intuito de confrontar essas formas de sociabilidade utilizadas nestes dois contextos distintos. Diante do exposto, nossa discussão será embasada em pesquisas voltadas para a temática da utilização de mídias sociais online, bem como sobre as relações virtuais, configurando este estudo como uma netnografia, em que buscaremos analisar nos anúncios de homens gays no jornal Lampião da Esquina e no aplicativo Grindr, os sentidos atribuídos por estes sujeitos à midiatização do corpo na busca por parceiros em 
contextos históricos diferentes. Assim como de identificar os aspectos comuns no processo de busca por parceiros nestes meios de socialização e descrever quais parâmetros são utilizados com maior frequência na busca por parceiros nestes instrumentos.

\section{O advento da internet e a mercantilização de corpos gays: implicações sociais}

Assim como as discussões sobre a influência das tecnologias em nossas vidas, a temática do corpo transpassa as nossas vivências enquanto seres sociais. Estar em uma sociedade que cultua o corpo masculino enquadrado em padrões impostos pela sociedade, abre uma série de oportunidades de discussões sobre os diferentes corpos que habitam o mundo. Nesse sentido, o corpo enquanto ferramenta social é construído com a intenção de alcançar uma identidade que seja considerada adequada às relações socioculturais vigentes (SOARES; BARBOSA, 2020).

A construção identitária da imagem do corpo ideal pode ser observada levando em conta o ambiente social em que o indivíduo está presente, sua consciência corporal e as relações sociais com os outros indivíduos. Num contexto material, o corpo pode ser visto como um objeto material separado do indivíduo, que assim the atribui significado (THOMPSON; HIRSCHMAN, 1995b). Nesse sentido, vemos na expansão do uso da internet uma oportunidade de exposição e mercantilização do corpo, conforme exposto na citação a seguir.

Com a comercialização da internet, por volta de 1990, o cidadão começou a mudar comportamentos e ver transformações em corporações, na comunicação, e em seu próprio ser social. Com uma internet primitiva e estática, acessada por navegadores como o Internet Explorer, da Microsoft, o consumidor do início dos anos 2000 possuía poucas possibilidades de interação e expansão virtual, o que se via, mesmo arcaico, eram os chamados bate-papos, como MSN e ICQ, esboços do que vivemos hoje com inúmeras maneiras de se comunicar, que vão das redes sociais aos aplicativos. Estes últimos somam 1,43 milhão na Google Play Store e 1,21 milhão no Itunes Store (LAU; FERREIRA, 2015, p. 36).

Dentro dessa perspectiva, compreendemos o valor do corpo nas relações afetivas quando os sujeitos aqui apresentados utilizam seus próprios corpos em aplicativos de relacionamentos gays e no jornal Lampião da Esquina. Fazendo com que as relações sociais de cada indivíduo reforcem a sistematização de significados e práticas associadas ao corpo. Pois, o corpo representa um bem simbólico, recebendo diferentes valores a partir do contexto inserido (BOURDIEU, 2009). 
Podendo assim, o corpo passar a significar para o sujeito uma espécie de prisão, a qual teria como objetivo pressioná-lo a se adequar aos padrões sociais emergentes. Para um grupo de gays, não é necessário apenas possuir um corpo musculoso, ter braços definidos e aparência jovial, mas também usar o corpo para reforçar perante a sociedade e os seus pares um determinado tipo de masculinidade. O corpo desejado por esse grupo não é apenas o corpo do outro, mas o seu próprio corpo, pois o corpo desejado é espelho do seu, ou seja, um corpo de homem masculino, heterossexual e dominante (PEREIRA; AYROSA, 2012; OLIVEIRA, 2019).

Ao observar os anúncios e os perfis de homens gays na busca por parceiros, é visível a percepção do modelo de masculinidade apresentado e desejado na descrição dos perfis e anúncios. O corpo padronizado e esteticamente enviesado ao masculino heterossexual e musculoso incorporado pelos sujeitos nos dois campos de investigação resulta na composição identitária dos sujeitos, cada um em sua época, tendo por base a satisfação das relações de consumo, priorizando a mercantilização de corpos no mundo gay.

Eccel e Saraiva (2009) afirmam que embora as masculinidades homossexuais se refiram as masculinidades subordinadas ao parâmetro da representação da masculinidade hegemônica e heteronormativa, e tenham esta como base, é possível observar desníveis de poder e de legitimação entre as diversas masculinidades no meio homossexual. Nesse sentido, para cada sociedade, ou grupo social, há um ideal de masculinidade; para cada ideal de masculinidade, um corpo que estabelece, assim, uma relação entre a identidade de gênero e a construção do corpo (DUTRA, 2007). Assim, são instituídos modelos convencionais de atuação social, que orientam a vida das pessoas em suas relações cotidianas, conforme descrito a seguir para as formas de atuação e performances de homens gays, em especial nas suas interações digitais.

Assim, a mídia enquanto exposição do homossexual perfeito, caracteriza o pensamento construído por muito tempo, tal como: intelectual, branco, classe média ou alta, com gostos refinados e de boa aparência. Sendo considerado o contrário a imagem do homem afeminado, com trejeitos que se assemelham ao ridículo, mau gosto e banalização. Caracterizando reflexo do pensamento que guiou sua construção. O contrário desta imagemmodelo é personificado por um homem efeminado, não necessariamente jovem, com trejeitos que se aproximam do ridículo, cujas roupas ou delatam seu pouco capital econômico, ou são de mau gosto e com preocupações banais (SILVA, 2018).

Os padrões apresentados como parâmetros a serem seguidos engendram disputas dentro dos próprios grupos marginalizados socialmente, causando uma dicotomia claramente 
visível dentro do próprio grupo, assim temos um confronto claro entre os considerados "afeminados" e "padrõezinhos", ricos e pobres, brancos e negros, dentre outras infinitas formas de divisão nas lutas identitárias. Essas configurações imprimem formas específicas e subjetivas de enfrentamento às adversidades que especialmente os gays enfrentam nas suas vivências diárias.

Os enfrentamentos às imposições sociais passam por uma série de questões que transpassam temas como classe, raça e gênero dentro do atual modelo social. Dessa forma, quando pensamos as interações realizadas no mundo virtual compreendemos como tudo pode ser comprado e adquirido. Nessa concepção, a felicidade passa a ser compreendida como uma imposição social que é compartilhada nas redes sociais, tornando a vida um espetáculo a ser mais do que vivido, a ser assistido e consumido (ANDRADE; SILVA, 2019).

Para tanto, os sujeitos ao fazerem uso das mídias digitais sentem a necessidade de se projetar da melhor maneira possível, expondo em seus perfis o melhor de si, apresentando um verdadeiro currículo, onde suas melhores características são expostas com o objetivo de obter a partir disso um relacionamento. Eles se preparam por meio de um breve script que lhe é oferecido pela própria ferramenta (aplicativo), que não propõe falha e que promete, como um produto, bom desempenho (ANDRADE; SILVA, 2019; OLIVEIRA, 2019).

Os perfis dos aplicativos servem como vitrine de venda do produto que, nesse caso, é a própria imagem, cabendo ao seu administrador a melhor forma de expor suas características. Essa analogia que utilizamos possibilita uma leitura facilitada do funcionamento dos aplicativos de encontro, seja ele qual for. Nesse contexto, alguns aspectos imprimem maior visibilidade aos perfis exibidos nos aplicativos, a imagem é um destes artifícios. Ao analisar sites de encontros gays, imagens são caracterizadas na construção de uma masculinidade singular, segundo os padrões de uma virilidade, considerada saudável. Nessa produção, lê-se “Os homens mais bonitos disponíveis pra você!” Não há, aqui, nenhum resquício de uma gramática da diversidade: homens, [...]” (JUNIOR, 2014, p. 45), diante dessa colocação vemos uma clara imposição dos padrões estéticos e sociais exigidos para que se possa ter uma melhor desenvoltura nas interações virtuais.

A exposição de imagens nos perfis é o que gera maior ou menor visualização e procura por parte dos outros usuários do aplicativo. Soares e Barbosa (2020, p. 234) destacam o seguinte trecho sobre este assunto "o foco dos textos e das fotografias que estão nos perfis online é o corpo, descrito, fotografado e publicado como se estivesse submetido a uma espécie de "totalitarismo fotogênico"”. Assim, a centralização do corpo na capacidade de socialização dos sites pode compreender certa parte da história dos corpos, uma vez que, o 
corpo e seu desempenho, suas performances e sua aparência são os elementos constitutivos dos encontros e das interações oferecidas (ZAGO, 2013).

A veiculação de imagens expõe dentro das pesquisas no campo virtual uma série de informações que por vezes poderiam não estar visíveis em uma etnografia offline. Por isso, nos referimos a descrição realizada pelos usuários de aplicativos em relação às características que são consideradas importantes na apresentação aos seus pares, conforme descrito no comentário a seguir.

Chamam a atenção, de imediato, algumas "características" comuns a todos: são usuários que se descrevem como ativos (apenas um deles se coloca como "versátil", ativo e passivo), que possuem pênis avantajados devidamente comentados e expostos e que se apresentam e exigem "discrição" e "masculinidade". A expressão que é mais comum e que subsumi todos esses atributos é "macho ativo". As identidades que tangenciam esse discurso do "macho ativo", então, serão engendradas a partir de uma encenação discursiva do corpo, que aparece em texto e em imagens materializados em pênis devidamente mensurados e nos músculos que exibem um paradigma de beleza para o dispositivo sexual contemporâneo (JUNIOR, 2014, p. 318).

As performances realizadas no mundo virtual engessam os sujeitos de tal forma que somente os perfis com as descrições que se enquadram nos modelos desejados possuem maior acesso. Sendo importante focar nos aspectos que aumentam as chances de conseguir um parceiro. As fotografias apresentadas visivelmente consideram o fato de que apenas suas partes relevantes são expostas, ao passo que outras são invisibilizadas. É recorrente nos perfis a publicação de fotografias de peitorais, abdominais, braços, glúteos e pênis. Em muitos desses perfis, as faces e as cabeças dos usuários não são tão intensamente expostas (ZAGO, 2013).

O fato de não expor o rosto perpassa entre outros fatores a questão do sigilo, que é na maioria das vezes pré-requisito para conseguir um encontro real. As regras de interação entre sujeitos virtuais demandam dos usuários de aplicativos a adequação às diversas normas, dentre elas a maneira de exibição dos corpos nos perfis tem seu lugar de valor, pois como bem pontua Zago (2013), estes corpos ganham centralidade graças ao seu tônus muscular, à lisura da sua pele, à inexistência de gordura, ao relevo esculpido por meio de exercícios físicos algo que institui uma conotação 'quase moral', fornecendo os critérios de avaliação individual. Como podemos observar, o que está em jogo na procura por um parceiro nos aplicativos é necessariamente o enquadramento nos requisitos impostos no padrão de beleza exigido socialmente. Assim, diante de uma vitrine onde são expostos diferentes produtos, o sujeito avalia quais são os melhores e, consequentemente, lançam suas propostas de interação. 
Essas reflexões apontam que tais discursos também propõem corpos idealizados, gerando questões de exclusão aos que não se inserem nos estereótipos propostos. Ao assumir e externar o desejo de relacionar-se com pessoas que tenham um determinado porte físico, condição financeira estável, endereço residencial bem localizado e que possua transporte, percebemos a reprodução de um discurso marcadamente hierárquico, em que ativos e passivos encenam formas de sujeito incomensuráveis (JUNIOR, 2014).

Todo esse emaranhado de interações virtuais engendra a teia que possibilita entender a forma que se constroem as sociabilidades virtuais no campo da busca por parceiros. Notando que a exposição por meio de fotografias constitui um destes aspectos, quando muito se expõe os atributos físicos nos perfis existe claramente uma intenção e desejo, dessa forma, os sentidos atribuídos a tais práticas dizem muito sobre os sujeitos pesquisados, conforme podemos perceber na fala abaixo.

Publicar fotografias em que aparecem somente abdomens, peitorais e braços trabalhados em exercícios de musculação, em que a cabeça é "cortada" do corpo, é uma operação que visa traduzir na carne as informações pertinentes sobre o corpo. É fazer do corpo, ou de algumas de suas partes, a encarnação máxima daquilo que é mais importante nos indivíduos. É exibir partes do corpo trabalhadas através do que Courtine considera "práticas destinadas a demonstrar uma integração às normas corporais em vigor, a fornecer um testemunho da comunhão com a cultura do corpo" em um contexto em que, segundo o autor, "O músculo é um modo de vida (ZAGO, 2013, p. 15).

Dentre os vários aspectos que envolvem essa discussão, vemos ainda uma grande distinção e recorrente perpetuação de preconceitos em relação aos papéis desempenhados na prática sexual, imprimindo dessa forma uma hierarquização dos papéis, no sentido de sempre colocar em xeque as dualidades que perpassam essas relações, tais como, ativo/passivo, afeminado/macho, musculoso/normal. É comum o descarte e recusa a parceiros que tenham trejeitos femininos ou mesmo que se identifiquem como afeminados, essas categorias sofrem não apenas nas vivências offline quando são alvo de piadas e, principalmente, de violência acarretada pela homofobia. Nos espaços virtuais é normal a busca por parceiros que não se identificam como gays e que estejam à procura de sexo sigiloso, corroborando com a noção do imaginário gay de que "existe a suposição de que, uma vez fora do "armário", um homem gay "perde" sua masculinidade; ao passo que se continuar dentro do "armário", sua virilidade ainda estará resguardada" (ZAGO; SANTOS 2011, p. 41).

Assim, a partir das construções sociais que definem papéis para cada gênero, na comunidade homossexual são impostas posturas onde se considera a atuação do ativo como uma performance mais masculina e que tem nessa forma de desempenho a postura do homem 
macho, que deve cumprir com seu papel de ativo, por ser este o papel social para quem nasceu com essa designação biológica. Essa visão do ativo é valorizada de forma a colocar os sujeitos que a praticam como os mais desejados nos aplicativos, carregando de estigmas e preconceitos os que não agem de tal forma, e principalmente perpetuando preconceitos que envolvem tudo o que está ligado à figura feminina, em detrimento do enaltecimento das práticas machistas e patriarcais.

Por outro lado, o homossexual ativo tende a ganhar status de mais macho, chegando ao ponto de, em raras exceções, os machos que "comem bichas" não serem classificados de maneira diferente dos "homens verdadeiros", devido ao seu desempenho do papel ativo. Inclusive, muitos homens que têm relações homossexuais não se consideram homossexuais, desde que não pratiquem o sexo anal ou que exerçam o papel "ativo" na relação sexual, pois o sujeito que se permite passivo na relação sexual com outro é tido como desvirilizado e passa a ser desqualificado enquanto cidadão (ALMEIDA, 2011).

Outra postura que é claramente percebida nas interações virtuais refere-se a práticas de racismo e de fetiches do corpo de gays negros. Essa é uma questão amplamente discutida pelos pesquisadores do tema, e que atualmente tem grande repercussão, mas que ainda é recorrente nas diversas situações do nosso cotidiano. No campo virtual não é diferente, sujeitos negros enfrentam uma gama de situações em que se destila ódio e preconceito a estes corpos, são situações que ultrapassam marcadores, pois, sempre estão no centro das discussões que envolvem minorias e grupos marginalizados.

Essa situação criada socialmente e que alimenta o imaginário das pessoas sobre as atuações do negro na prática sexual, possibilita um maior enraizamento de preconceitos. E dentro da comunidade gay, onde já se tem essas vivências de preconceitos e principalmente de violências causadas pela homofobia, é essencial a discussão dessas práticas e adoção de medidas que levem a conscientização da comunidade LGBTQIA+ em relação às discussões que envolvem as pautas sobre minorias e suas reivindicações.

Como bem pontuado por Barros e Barreto (2018, p. 310):

Todo negro é bom de cama", "Todo negro tem um pau grande" Eis que o (pre) conceito se manifesta no campo do corpo negro e da sexualidade. Por meio dessas afirmativas todo homem negro estaria fadado à prova concreta dessa fantasia imaginária no contexto erotizado da sexualidade e do corpo como objeto. [...] A construção do imaginário social, coisificado como objeto e mercadoria que se comprava, alugava e vendia para o uso (de todas as formas) pelos seus senhores e senhoras de engenho se configuram nas produções das fantasias de corpos negros. 
O que nos leva à compreensão, o uso da internet e das mídias digitais se entrelaçam com a vida real e nos fazem compreender como nascem as novas formas de sociabilidades no mundo contemporâneo. As lutas das pessoas que não "cumprem" as regras e exigências sociais impostas relativas aos papéis sexuais cisheteronormativos são lutas diárias, muitas dessas pessoas saem de suas casas, do seio da família por não serem aceitas, assim, se veem obrigadas a se prostituir para sobreviver, como é o caso de muitas trans. Neste sentido, alguns são obrigados a optarem por viver no armário, expressão utilizada por gays para designar aqueles que não são assumidos, ou assumirem sua identidade e viver da forma que lhes traz felicidade e revela seu verdadeiro eu. No mundo virtual, os que estão no armário se valem de artifícios que favorecem o anonimato.

Quando nos referimos aos sujeitos não assumidos temos uma gama de possibilidades e motivos que os fazem continuar a manter a opção por não se revelar. É válido destacar que em alguns casos, esses sujeitos sofrem ameaças, até mesmo de morte, por parte de pessoas da própria família e essa situação faz com que prefiram continuar a esconder sua verdadeira identidade. Em outros casos, existem sujeitos que por receio da reação de amigos, familiares, colegas de trabalho, preferem passar a imagem de heterossexual, em alguns casos mantendo relacionamentos heteronormativos ao mesmo tempo em que praticam sexo com outros homens. Nestas situações a utilização de aplicativos de encontro voltados para o público gay suprem as necessidades destes sujeitos pois,

Diferentemente dos espaços "reais", a Internet permite uma maquiagem da identidade desses indivíduos, com nomes falsos, sem fotos ou com fotos alheias. Este gueto, portanto, criou outra possibilidade para os "enrustidos" que têm medo de serem descobertos. Esse receio provoca o rechaço àqueles que assumem sua sexualidade, já que, na companhia de alguns desses assumidos, conclui-se com frequência que só andam "semelhantes" (ALMEIDA, 2011, p. 42).

Essas questões que envolvem a dicotomia público/privado são aspectos que enriquecem as discussões sobre os papéis desempenhados no campo virtual. Essa problematização nos abre uma infinidade de possibilidades de compreender as interações e principalmente esse novo modelo de sociabilidade homoafetiva. Um aspecto que cabe destacar é a questão da segregação dos sujeitos, quando eles, mesmo tendo hoje a oportunidade de frequentarem locais não voltados exclusivamente para esse tipo de público, não conseguem se sentir à vontade e por isso, continuam trazendo a vivência do que no passado eram os guetos, onde somente aqueles grupos marginalizados frequentavam e podiam ser quem realmente eram. 
Vale ressaltar que mesmo como os avanços que a comunidade gay obteve ao longo desses mais de quarenta anos de luta organizada, ainda assim devido a toda uma estruturação social que impõe um modelo de sexualidade a ser seguido, muitas pessoas não se sentem à vontade para assumir suas verdadeiras identidades, necessitando utilizar-se de artifícios nos aplicativos como os chamados nicknames ou apelidos, para poderem se relacionar. Dessa forma podemos visualizar diferentes aspectos que destacam os sentidos e significados atribuídos pelos sujeitos em suas relações virtuais.

$\mathrm{O}$ apelido torna-se uma etiqueta com informações relevantes sobre cada usuário das salas de bate-papo. Na tentativa de assegurar o anonimato, os indivíduos dissimulam seus nomes 'reais' criando nomes fictícios para si; assim, nesses apelidos há informações supostamente tão 'verdadeiras' sobre si quanto seus nomes 'reais', pois nos apelidos há menções sobre seus corpos, suas idades e, inclusive, sobre suas práticas sexuais. É assim que o apelido, dentro das salas de bate-papo da internet, pode não ser fictício: ele pode ser bastante 'real' (ZAGO; SANTOS, 2011, p. 55).

A forma que esses sujeitos se escondem e buscam meios digitais para se relacionar, dizem muito sobre eles. Esses pequenos detalhes são essenciais para conhecer a dinâmica que buscamos analisar e compreender, além de oportunizar um melhor entendimento de como se dão as conexões virtuais no sentido de proporcionar o estreitamento de laços entre pessoas. A utilização dessas ferramentas indica também uma fragilidade no que tange a superficialidade do fortalecimento das relações digitais, podemos notar uma maior fluidez no trato com os pares, quando ao iniciar uma conversa com um sujeito, em certa altura do diálogo virtual se houver um confronto de ideias ou pontos de vista totalmente opostos, um dos dois envolvidos pode simplesmente excluir o outro de sua lista de contatos, indicando assim um tratamento descartável do outro no campo virtual, corroborando com essa visão de que as mídias digitais oferecem uma noção das atuações sociais atuais.

O uso intensificado de aplicativos móveis para relacionamentos nos coloca frente a uma das mais sensíveis transformações sociais do presente, incidindo sobre a forma como temos constituído novos horizontes aspiracionais relativos a desejos sexuais e afetivos marcadas por desafiantes negociações sexuais e de gênero, aprendizados tecnológicos. Estes incidem fortemente nas nossas formas de sentir e administrar emoções, além de exigir todo um aprendizado para lidar com modos/etiquetas de comunicação que estão sendo constituídos ao mesmo tempo em que são articulados. Isto é, temos sido levados a acionar esses códigos relacionais no momento mesmo que os colocamos em prática. Vale para quem está nos aplicativos em busca de sexo, companhia ou amor (PELUCIO, 2017, p. 321). 
Essas reflexões servem para nos fazer pensar as nossas próprias vivências no contexto atual. Pensar o nosso modo de vida a partir de um olhar do campo virtual para o real, é válido porque expõem os sujeitos na sua essência, são nos perfis de aplicativos e nas redes sociais que exibimos nossos desejos mais íntimos e que são explorados só as coisas boas como: viagens, casas luxuosas, corpos perfeitos, melhores festas, o carro do ano, lá alimentamos o nosso ego, envolvendo desejos que compreendem os aspectos econômicos, sociais, e sexuais que alimentamos. O campo do virtual compreende dessa forma uma extensão do real que diz muito sobre cada um.

\section{Procedimentos metodológicos}

Por considerarmos o problema e, sobretudo, os objetivos que almejamos alcançar com o estudo, trabalhamos com uma pesquisa netnográfica, a qual é uma forma especializada de etnografia que utiliza comunicações mediadas por computador como fonte de dados para chegar à compreensão e à representação etnográfica de um fenômeno cultural na Internet. Sua abordagem é adaptada para estudar fóruns, grupos de notícias, blogs, jornais, redes sociais etc. (KOZINETS, 2014).

Nas condições postas, entendemos que o referido tipo de pesquisa substancia a produção de respostas a problemática suscitada neste estudo. Desse modo, os dados foram produzidos mediante a captura de dados arquivais ${ }^{6}$ de três perfis no Jornal Lampião da Esquina e três no Aplicativo de encontros Grindr.

As informações capturadas dos dados arquivais dos três perfis no Jornal Lampião da Esquina e três no Aplicativo de encontros Grindr foram analisados por meio da abordagem interpretativa quando o foco da investigação são as significações da ação humana frente a contextos culturais específicos, proposta por Gaskins, Miller e Corsaro (1992). Dessa forma, foi realizada uma análise-síntese dos dados no intuito de obtenção das principais mensagenschave. Em seguida, foram analisados os perfis e extraído as informações relevantes à compreensão do objetivo e problema da investigação.

${ }^{6}$ São dados coletados diretamente de comunicações mediadas por computador dados da página, blog, jornais, aplicativos de encontros, site da comunidade ou grupo observado, assim como fotografias, trabalhos de arte e arquivos de som, dados cuja criação e estimulação o pesquisador não esteja diretamente envolvido. 


\section{Entrelaçando formas de socialização homoeróticas no Lampião da Esquina e Grindr.}

Analisaremos aqui três anúncios da coluna "troca troca" do jornal Lampião da Esquina, que foi o primeiro jornal alternativo homoerótico brasileiro que circulou durante os anos de 1978 e 1981. Nasceu dentro do contexto de imprensa alternativa na época da abertura política de 1970, durante o abrandamento de anos de censura promovida pelo Golpe Militar de 1964 (BANDEIRA, 2006). Em formato tabloide, o jornal tinha editoriais fixos como "Cartas na Mesa", onde as cartas dos leitores eram publicadas e respondidas, "Esquina" onde eram reunidas notícias, "Reportagem", onde sempre a matéria de capa estava localizada, e a partir do número cinco a coluna "Bixórdia". Além dessas sempre havia espaço para informações culturais, como indicações de livros, exposições, shows e filmes; e para entrevistas. A produção do conteúdo era feita pelos conselheiros editoriais e por convidados que variavam a cada edição (MOTTA, 2009).

A coluna "troca troca" foi idealizada no formato de classificados, no entanto, seu intuito era possibilitar que os leitores do jornal pudessem conhecer outras pessoas com os mesmos gostos, hobbies e preferências. Na coluna, que cobrava uma pequena taxa para veiculação do anúncio, podiam escrever tanto homens como mulheres, exibindo suas características que considerassem mais importantes para que os demais leitores tivessem conhecimento. Abaixo apresentamos um fragmento do jornal que destacamos para a análise.

Figura 1 - Sessão “Troca/troca” Edição 021-Fevereiro-1980

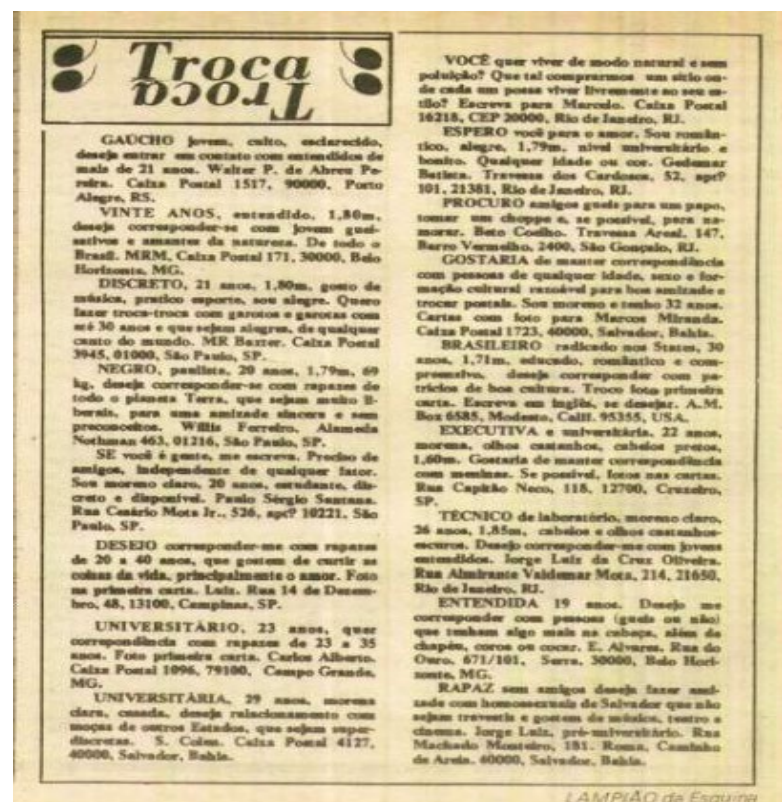

Fonte: Grupo Dignidade (2020) 
Nosso segundo objeto de estudo é o aplicativo Grindr - um ambiente de comunicação e de sociabilidade gay online lançado no ano de 2009, funcionando na lógica location-baseadreal-time (LBRTD) (LANDOVITZ et al., 2012). Este aplicativo conta com cerca de 3.6 milhões de usuários em 192 países. A plataforma é uma ferramenta simples de interação, na qual é possível obter informações sobre os usuários mais próximos, como sua distância, fotos, altura, peso, "tribos" a que pertencem e chat. É usado com as mais diversas finalidades, como interação social, sexo, inclusão social, entretenimento, dating, tendo recebido atenção em estudos sobre comportamentos sexuais considerados de risco (RICE et al., 2012; LANDOVITZ et al., 2012). Apresenta características de "vilas gays", nas quais os sujeitos usam símbolos e sinais próprios para se fazerem visíveis entre eles e invisíveis na sociedade (AHLM, 2017). Sua escolha se deu por ser um dos aplicativos de encontro mais popular voltado para o público de homens gays.

A seguir apresentamos a imagem dos três perfis que analisaremos.

Figura 2 - Perfis de usuários do Grindr
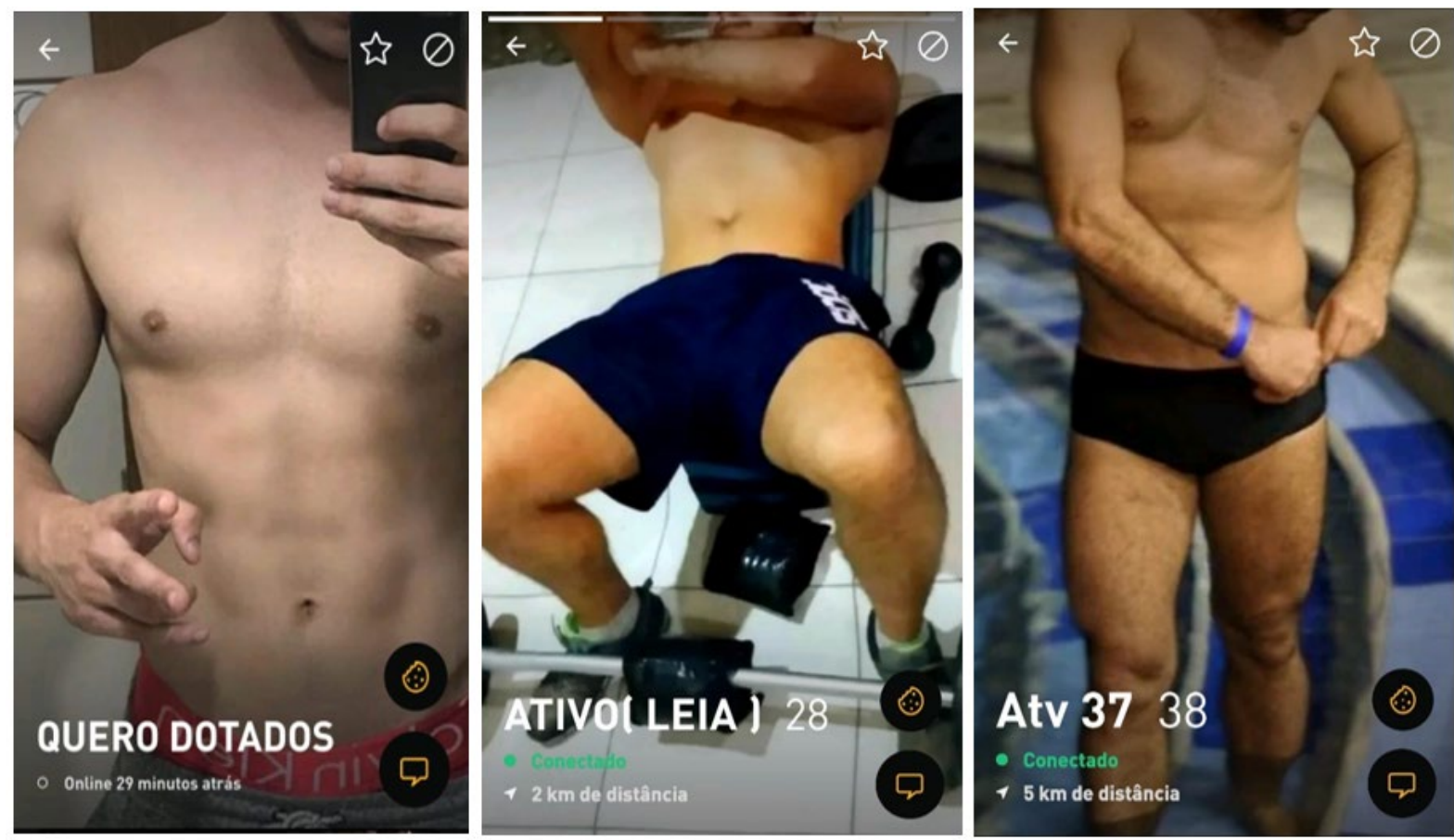

Fonte: Grindr (2020)

A partir da seleção dos anúncios e dos perfis iniciamos a construção das categorias de análise, para tanto, realizamos a estruturação das falas dos sujeitos selecionados, com o intuito de organizar as categorias e discorrer sobre cada uma delas fazendo relação com as leituras realizadas sobre o tema. No quadro a seguir, destacamos os anúncios dos três sujeitos 
escolhidos no Lampião da Esquina. É importante frisar, que o momento e a realidade desses sujeitos era totalmente distinta da atual, no entanto, já era possível perceber a existência de parâmetros considerados válidos para a veiculação de anúncios que buscavam proporcionar uma interação social. Aspectos que descrevem comportamentos, gostos, intenções desejadas, marcadores como raça e geração são claramente identificados nos perfis apresentados abaixo, corroborando com a compreensão do valor simbólico atribuído aos sujeitos naquele momento histórico (BOURDIEU, 2009).

\title{
Quadro 1 - Anúncios selecionados na seção Troca-Troca no Lampião da Esquina
}

SUJEITO 01 - Discreto, 21 anos, $1.80 \mathrm{~m}$, gosto de música, pratico esporte, sou alegre. Quero fazer troca-
troca com garotos e garotas com até 30 anos e que sejam alegres, de qualquer canto do mundo. MR
Baxter. Caixa Postal 3945, 01000 , São Paulo, SP.
SUJEITO 02 - Negro, paulista, 20 anos, $1,79 \mathrm{~m}$, deseja corresponder-se com rapazes de todo o planeta
terra, que sejam muito liberais, para uma amizade sincera e sem preconceitos. Willis Ferreiro, Alameda
Nothmann 643,01216 , São Paulo, SP.
SUJEITO 03 - BRASILEIRO radicado nos STATES, 30 anos, 1,71m, educado, romântico e
compreensivo, deseja corresponder com patrícios de boa cultura. Troco foto primeira carta. Escreva em
inglês, se desejar. A. M. Box 6585, Modesto, Calif. 95355, USA.

Fonte: Lampião da Esquina (1980)

Já nos perfis selecionados no aplicativo Grindr, notamos uma maior variedade de informações que apresentam diversos marcadores para se pensar as interações realizadas nessa ferramenta. Os sujeitos selecionados apresentam de forma clara suas preferências e exibem em seus perfis as fotos de seus corpos malhados. Os marcadores que sinalizam os aspectos que conversam com as categorias analisadas são percebidos facilmente ao observamos os perfis, geração, porte físico e raça, além das preferências que são destaques nestes perfis. As informações expostas nos perfis dos usuários do Grindr além de corroborar com nossa pesquisa imprimem uma série de outras provocações às quais não iremos nos ater neste trabalho, mais que são importantes de se destacar. Perfis que apresentam sujeitos que destacam aspectos como magreza, velhice, gordos, afeminados, assumidos, entre outros são descartados instantaneamente.

\section{Quadro 2 - Perfis selecionados no Grindr}

\author{
SUJEITO 04 - ATIVO [LEIA] NOVINHOS, ATIVOS, sem fotos, fumantes, gouines, afeminados, \\ magrelos, fakes e drogados. \\ NÃO CURTO PEGAÇÃO ENTRE ATIVOS \\ Discreto, boa aparência, distenso e educado, em busca de semelhantes \\ $1,72,72 \mathrm{~kg}$. latino, torneado, ativo, discreto, solteiro, negativo.
}

SUJEITO 05 - Atv. 37, Ativo afim de curtir algo legal, seja encontro, papo, cerveja, sexo, passeio ou tudo junto. Chega aí! 
x Ativos afim de pegação

$\mathrm{x}$ afeminados

1,70, $75 \mathrm{~kg}$, branco, torneado, homem, ativo, discreto, solteiro, encontros, amigos, agora, negativo.

SUJEITO 06 - QUERO DOTADOS, SÓ CURTO: novinhos, malhados, magrinhos ou sarados, machos, discretos.

X NÃO CURTO: afeminados ou assumidos, gordos, velhos.

NÃO MANDO FOTO DE ROSTO!

NÃO RESPONDO PERFIL SEM FOTO!

NÃO TENHO PACIÊNCIA!

1,82 , branco, homem, malhadinho.

Fonte: Grindr (2020)

Diante do confronto dos anúncios e dos perfis elegemos duas categorias para analisarmos, assim buscamos acentuar o sentido de compreender o lugar que o corpo ocupa nessas formas de socialização, e como a partir dessas ferramentas esse corpo torna-se um objeto de mercantilização, na busca por um parceiro. Dessa forma, dividimos os marcadores que representam cada categoria e organizamos em quadros analíticos para possibilitar a compreensão dos leitores.

Quando comparamos os anúncios/perfis não notamos uma diferença considerável entre os aspectos que imprimem esses marcadores. Se observarmos a categoria corpo, perceberemos que os mesmos aspectos destacados pelos anunciantes no Lampião da Esquina, ainda são considerados relevantes nos perfis no Grindr. Os destaques informados pelos sujeitos igualam-se quando estes apresentam aspectos como altura, comum a todos os anúncios/perfis, peso, destacado em dois dos perfis no Grindr, além, de práticas esportivas ou porte físico, imprimindo desta forma uma noção do corpo como objeto mercadológico (THOMPSON; HIRSCHMAN, 1995a), como apresentado no quadro a seguir.

\section{Quadro 3 - Categoria - Corpo}

\begin{tabular}{|l|l|}
\hline & S 01 $-1.80 \mathrm{~m}$, pratico esporte. \\
& S 02 $-1,79 \mathrm{~m}$. \\
& S 03 $-1,71 \mathrm{~m}$. \\
& S 04 $-1,72,72 \mathrm{~kg}$, boa aparência, torneado. \\
& S 05 $-1,70,75 \mathrm{~kg}$, torneado. \\
S 06 $-1,82$, malhadinho.
\end{tabular}

Fonte: Elaborado pelos autores

$\mathrm{Na}$ categoria mercantilização há mais atribuições a outros aspectos que especificamente ao corpo. Especialmente nos usuários do Lampião da Esquina, há uma valorização com as preferências pessoais, como gostos e hobbies, que demarcam de forma muito sútil essa categoria. Contrapondo essa visão dos sujeitos anunciantes do Lampião da 
Esquina, os usuários do Grindr por sua vez expõem claramente aspectos que apresentam essa conotação mercantil do corpo, apresentando marcadores como altura, peso, preferências e como destacado pelo Sujeito 06 o que não o atrai.

\section{Quadro 4 - Categoria - Mercantilização}

\begin{tabular}{|l|l|}
\hline & S 01 - gosto de música, pratico esporte, sou alegre. \\
S 02 - deseja corresponder-se com rapazes de todo \\
o planeta terra, que sejam muito liberais, para uma \\
amizade sincera e sem preconceitos. \\
S 03 - educado, romântico e compreensivo, deseja \\
corresponder com patrícios de boa cultura. Troco \\
foto primeira carta. Escreva em inglês, se desejar. \\
S 04 - Discreto, boa aparencia, distenso e educado, \\
em busca de semelhantes, 1,72, 72 kg. latino, \\
torneado, ativo, discreto, solteiro, negativo. \\
SERCANTILIZAÇÃO & ativo, discreto, solteiro, encontros, amigos, agora, \\
& negativo. \\
S 06 - QUERO DOTADOS, SÓ CURTO: \\
novinhos, malhados, magrinhos ou sarados, \\
machos, discretos. \\
X NÃO CURTO: afeminados ou assumidos, \\
gordos, velhos. \\
NÂOMANDO FOTO DE ROSTO! \\
NÃO RESPONDO PERFIL SEM FOTO! \\
NÃO TENHO PACIÊNCIA!
\end{tabular}

Fonte: Elaborado pelos autores

Os desenhos que traçamos a partir das análises e reflexões aqui realizadas nos levam a perceber uma semelhança entre os sujeitos das duas ferramentas, no que diz respeito às formas de exposição dos corpos e o sentido dado a mercantilização destes. Os principais marcadores que indicam essa proximidade entre os anúncios e perfis analisados são os aspectos como altura e porte físico, principalmente referentes ao corpo, e gostos, aparência, preferências pessoais, no que tange a mercantilização. Assim, os perfis analisados têm apresentado uma maior exposição e consequente desejo por corpos perfeitos e malhados, se comparados aos considerados fora do padrão. Consoante às discussões propostas até aqui, podemos perceber a configuração das dinâmicas de interações sociais por meio das ferramentas nos dois contextos apresentados.

\section{Considerações finais}

Atualmente, as ferramentas tecnológicas permitem que estejamos conectados o tempo todo, essa é a nova configuração social e virtual da contemporaneidade, sendo consideradas 
imposições porque o não uso de uma ou outra dessas ferramentas nos faz ser taxado de ultrapassado, velho e antigo. O contexto social no qual estamos inseridos nos molda e orienta no sentido de estarmos alinhados às práticas correntes que nos possibilitam participar efetivamente nos modos de vida social daquele tempo.

Considerando as formas de sociabilidade para homens gays em épocas distintas, tentamos compreender como são tratados os temas que atravessam as questões do corpo, identificar os aspectos mais comuns no processo de busca por parceiros nesses ambientes e descrever quais parâmetros são utilizados com maior frequência na busca por parceiros nestes instrumentos. Olhando atentamente os perfis apresentados, tanto dos usuários do Lampião da esquina, quanto do Grindr, percebemos semelhanças nas maneiras de se apresentar, onde são descritos, em sua maioria, aspectos que exaltam e destacam o corpo e em consequência suas preferências e gostos.

Especificamente ao tratarmos das categorias aqui apresentadas, a saber, corpo e mercantilização, os sujeitos observados apresentam aspectos que se entrelaçam e se confundem independente da época. Ao lançarmos um olhar atento aos resultados observamos o corpo nos dois casos estudados é atravessado por categorias que imprimem uma necessidade de torná-lo perfeito, desejável, sendo estes modelos de corpos os mais buscados pelos sujeitos em busca de parceiros. Em relação aos aspectos e parâmetros utilizados na busca por parceiros temos novamente um emaranhado de conexões que se interligam, para tanto, aspectos como porte físico, gostos semelhantes, padrões de vida, raça, entre outros, são considerados de suma importância na procura por um parceiro, seja no jornal, ou no ambiente virtual, por meio de aplicativos, onde percebemos além de uma grande exposição do corpo, o intuito de apresentar este como uma forma de mercadoria, no sentido de expor suas melhores atribuições e qualidades.

Dessa maneira, ao refletirmos sobre os sentidos atribuídos às formas de socialização de homens gays em dois momentos diferentes da história, podemos inferir que as práticas utilizadas se assemelham no destaque atribuído ao corpo e ao fator mercantil de tal, portanto, sendo basicamente o corpo enquanto físico e esteticamente agradável o mais atrativo na escolha deles.

\section{REFERÊNCIAS}

AHLM, J. Respectable promiscuity: digital cruising in an era of queer liberalism. Sexualities, v. 20, n. 3, p. 364-379, 2017. 
ALMEIDA, D. M. Vi. Sou gay, porém totalmente discreto: os estereótipos e a criação do ethos em um site de relacionamento gay. ReVeLe, v. 6, n. 3, p. 34-46, 2011.

ANDRADE, E. R; SILVA, T. T. Excesso e positividade na constituição do sujeito: uma reflexão sobre aplicativos de relacionamento. Revista Mídia e Cotidiano, Artigo Seção Livre, v. 13, n. 3, p. 23-31, 2019.

BANDEIRA, M. L. G. Será que ele é? Sobre quando Lampião da Esquina. colocou as Cartas na Mesa. 2006. Dissertação (Mestrado em História) - Pontifícia Universidade Católica de São Paulo, São Paulo, 2006.

BARROS, P. E; BARRETO, R. M. Corpo negro e pornografa a fantasia do negro pauzudo. Bagoas - Estudos gays: gêneros e sexualidades. v. 19, n. 3, p. 301-315, 2018. BOURDIEU, P. O senso prático. Petrópolis: Vozes, 2009.

DUTRA, J. L. Onde você comprou esta roupa tinha para homem? A construção de masculinidades nos mercados alternativas de moda, In: GOLDENBERR, M. (Org.). Nu e vestido: dez antropólogos revelam a cultura do corpo carioca. Rio de Janeiro: Record, 2007. p. $19-40$.

ECCEL, C. S.; SARAIVA, L. A. S. Masculinidade, auto-imagem e preconceito: um estudo das representações sociais de homossexuais. In: ENCONTRO ANUAL DA ASSOCIAÇÃO NACIONAL DE PÓS-GRADUAÇÃO E PESQUISA EM ADMINISTRAÇÃO, 33., 2009, São Paulo. Anais [...] São Paulo: ANPAD, 2009.

GASKINS, S. M, P. J; CORSARO, W. A. Theoretical and methodological perspectives. New directions for child development. San Francisco, CA: Jossey-Bass, 1992. v. 58.

JUNIOR, A. B. Corpo, masculinidade e efeminização: uma análise da produção dos sujeitos homossexuais on-line. Letras, Santa Maria, v. 24, n. 48, p. 303-322, 2014.

KOZINETS, R. V. Netnografia: realizando pesquisa etnográfica online. Porto Alegre: Penso, 2014.

LANDOVITZ, R. J; TSENG, C. H; WEISSMAN, M; HAYMER, M; MENDENHALL, B; ROGERS, K; SHOPTAW, S. Epidemiology, sexual risk behavior, anda HIV prevetion practices of men who have sex with men using Grindr in Los Angeles, California. Journal of Urban Health, v. 90, n. 4, p. 729-739, 2012.

LAU, H. D; FERREIRA, W. J. Estereótipos da comunidade gay enquanto ser virtual. In: ENCONTRO DE PESQUISA EM COMUNICAÇÃO, 7., 2015, Salvador. Anais [...]. Salvador, BA: Universidade Estadual da Bahia, 2015.

MOTTA, F. “À luz do Lampião”. Revista Júnior, v. 12, n. 2, p. 40-43, 2009.

OLIVEIRA, T. L. S. Um sorriso para foto: narrativas de uma ex-chacrete sobre a construção do hipercorpo pelo discurso. 2019. Monografia (Trabalho de Conclusão do Curso de Educação Física) - Universidade Federal do Piauí, 2019. 
PELÚCIO, L. Afetos, mercado e masculinidades contemporâneas: notas iniciais de uma pesquisa em aplicativos móveis para relacionamentos afetivos/sexuais. Contemporânea, v. 6, n. 2 p. $309-333,2016$.

PEREIRA, S. J. N; AYROSA, E. A. T. Corpos consumidos: cultura de consumo gay carioca. Organ. Soc., v. 19, n. 1, p. 45-67, 2012.

RICE, E; HOLLOWAY, I. W; WINETROBE, H; RHOADES, H; BARMAN-ADHIKARI, A; GIBBS, J; DUNLAP, S. Sex risk among young men who have sex with men who use Grindr, a smartphone geosocial networking application. Journal of AIDS and Clinical Research, v. 4, n. 2, p. 1-8, 2012.

SILVA, F. C. L. Rebolando para entender os memes: performatividade masculina e disputas identitárias em festas gays e linguagem da internet. Revista Habitus, v. 16, n. 1, p. 65-78, 2018.

SILVA, W. C; CORREIA, M. S. Racismo, preconceito e discriminação no futsal profissional piauiense. FIEP BULLETIN, v. 90, n. 1, p. 23-29, 2020.

SOARES, M. D; BARBOSA, J. F. O corpo ideal: representação de corpo na subjetividade e contemporaneidade. Doxa: Rev. Bras. Psico. e Educ., Araraquara, v. 22, n. esp. 1, p. 238 254, 2020.

THOMPSON, C; HIRSCHMAN, E. C. Understanding the Socialized Body: A poststructuralist analysis of consumers. Journal of Consumer Research, v. 22, n. 1, p. 4558, 1995a.

THOMPSON, C; HIRSCHMAN, E. C. Compreendendo o corpo socializado: uma análise pós-estruturalista das autoconcepções, imagens corporais e práticas de autocuidado dos consumidores. Journal of consumer Research, v. 22, n. 3, p. 89-107, 1995 b.

ZAGO, L. F; SANTOS, L. H. S. Corpo, gênero e sexualidades gays na corda bamba éticometodológica: um percurso possível de pesquisa na internet. Cronos: R. Pós-Grad. Ci. Soc., Natal, v. 12, n. 2, p. 39-56, 2011.

ZAGO, L. F. "Caça aos homens disponíveis": corpo, gênero e sexualidade na biossociabilidade gay online. Sexualidad, Salud y Sociedad - Revista Latinoamericana, v. 13, n. 2, p. 12-23, 2013. 


\section{Como referenciar este artigo}

CORREIA, M. S.; SILVA, M. A. Â.; LEITE, J. O.; OLIVEIRA, T. L. S.; RODRGUES, W. S. O corpo como mercadoria nos anúncios/perfis de Homens gays no Lampião da Esquina e no Grindr. Doxa: Rev. Bras. Psico. e Educ., Araraquara, v. 22, n. 2, p. 471-491, jul./dez. 2020. e-ISSN: 2594-8385. DOI: https://doi.org/10.30715/doxa.v22i2.14395

Submetido em: 06/05/2020

Revisões requeridas: $30 / 07 / 2020$

Aprovado em: 05/08/2020

Publicado em: 31/08/2020 